\title{
Reconciling Employee Dissimilarity And P-O Fit
}

Amy McMillan-Capehart, (Email: mcmillancapeharta@ecu.edu), East Carolina University Tará Burnthorne Lopez, Southeastern Louisiana University

\begin{abstract}
Organizational diversity and person-organization fit have been found to have both positive and negative effects on organizational outcomes. These negative consequences of diversity are often attributed to a lack of fit between traditional employees and employees who differ based on observable or unobservable characteristics. The positive consequences of $P$-O fit are attributed to a lack of diversity within an organization. Thus, the question emerges: "is it possible to have both a diverse workforce and one with high levels of $P$-O fit?" If so, then perhaps it is possible to harness the positive outcomes of diversity and $P-O$ fit and to minimize some of the negative consequences. We propose that the organizational climate and socialization tactics of the firm are a key factor in achieving balance between diversity and fit. We suggest that some organizational climates are better at embracing diversity than others and thus result in a higher level of $P$-O fit despite the degree of diversity among employees. In addition, we suggest that certain socialization tactics encourage inclusion and acceptance and thus result in a higher level of P-O fit despite the number of dissimilar employees. Accordingly, we offer a framework in which organizational climate and socialization tactics moderate the relationship between employee dissimilarity and perceptions of $\mathrm{P}-\mathrm{O}$ fit.
\end{abstract}

\section{INTRODUCTION}

ncreasing diversity in the U.S. population has lead to increasing diversity in the workforce. As a result managers are faced with the challenge of managing a diverse workforce for which there is no real precedence. Although research has demonstrated that employee diversity offers some positive outcomes such as increased creativity, productivity, and problem solving (Jackson, 1992; McLeod, Lobel, \& Cox, 1996; Richard, 2000; Watson, Kumar, \& Michaelson, 1993), diversity has also been found to offer some negative consequences such as conflict, turnover, infrequent communication, and lower job satisfaction (Tsui, Egan, \& O'Reilly, 1992; Wharton \& Barton, 1987; Zenger \& Lawrence, 1989). Commonly, the negative consequences are attributed to a lack of fit between traditional employees and employees who differ based on observable or unobservable characteristics, referred to as employee dissimilarity in the diversity literature.

Person-organization fit (P-O fit) research addresses the extent to which the employee and the firm share similar values (O'Reilly et al., 1991) and the employee feels that the firm is an ideal place to work (Kristof, 1996). Contrary to findings related to diversity, person-organization fit research has supported a positive relationship between P-O fit and job satisfaction, organizational commitment, and job intentions (Ashforth \& Saks, 1996; Jones, 1986; Richard \& Grimes, 1996; Riordan, Weatherly, Vandeberg, \& Self, 2001). However, like diversity, P-O fit has drawbacks. It has been suggested that the homogeneity associated with high levels of P-O fit within an organization reduces creativity and innovation (Milliken and Martins, 1996). Thus, the question emerges: "is it possible to have both a diverse workforce and one with high levels of P-O fit?" If so, then perhaps it is possible to harness the positive outcomes of diversity and $\mathrm{P}-\mathrm{O}$ fit and to minimize some of the negative consequences.

We propose that the organizational climate of the firm and the socialization factors implemented are key factors in achieving balance between employee dissimilarity and fit. We suggest that some organizational climates are better at embracing diversity than others and thus result in a higher level of P-O fit despite the degree of 
dissimilarity among employees. In addition, we suggest that certain socialization tactics can help organizations benefit from the positive effects of both diversity and P-O fit. At this point it is relevant to note that we are predominantly concerned with responses at the individual employee level. For this reason, , we focus on employee dissimilarity rather than firm-level diversity. Employee dissimilarity captures the relative difference between an individual employee and his or her colleagues based on particular characteristics (Hobman, Bordia, \& Gallois, 2003). Employee dissimilarity can be thought of as diversity at the individual employee level. Accordingly, we offer a framework (see Figure 1) in which organizational climate and socialization tactics moderate the relationship between employee dissimilarity and perceptions of P-O fit.

This research offers several contributions. First, very little research has examined the relationship between employee dissimilarity and perceptions of P-O fit. Second, no previous research has examined the moderating effect of organizational culture and socialization tactics on the aforementioned relationships. Third, this study provides insight into how organizations can achieve the benefits of diversity and P-O fit while eliminating the disadvantages.

Figure 1

Moderating Effects Framework

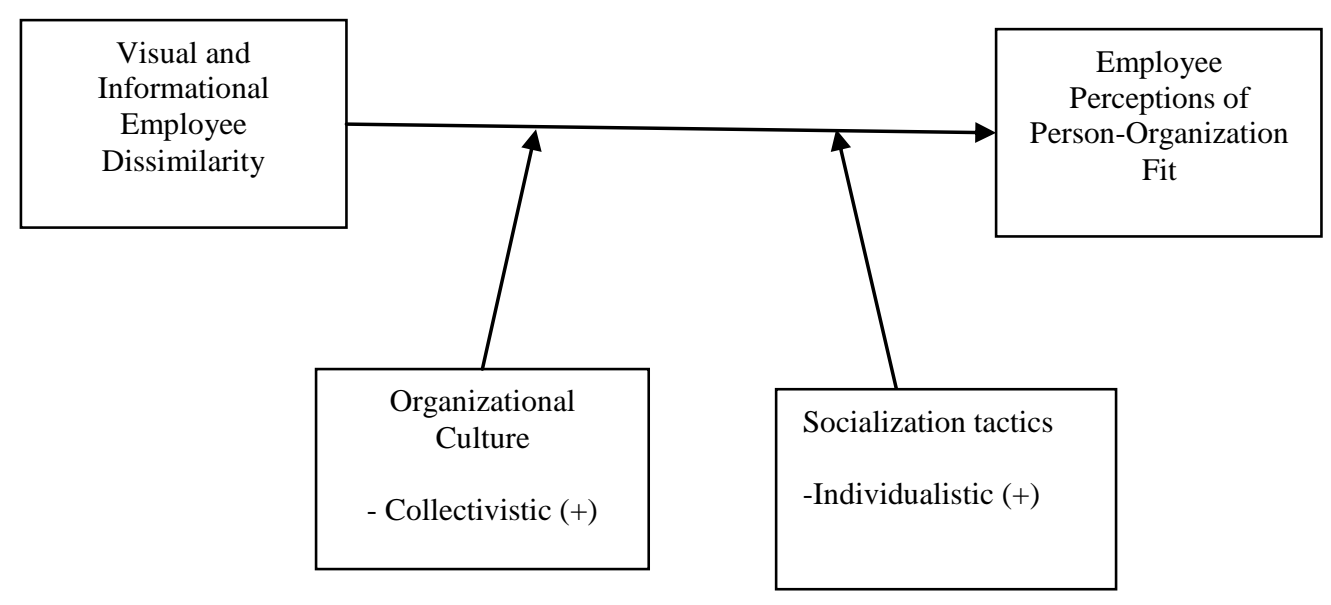

\section{CONCEPTUAL BACKGROUND AND PROPOSITIONS}

We begin by offering background for the focal constructs in this study - employee dissimilarity, personorganization fit, organizational climate, and socialization tactics. Next, we offer brief support of the hypotheses for the foundational relationships in this study including the relationships between employee dissimilarity and P-O fit. Finally, we offer theoretical rationale for the moderating relationships which are the focal point of this research.

\section{Employee Dissimilarity}

Diversity research encompasses multiple streams. One stream examines work-group or firm-level diversity while a second focuses on individual level differences, often referred to employee dissimilarity. The two streams are related but they have different foci. Diversity research focuses on the amount of diversity within a group whereas employee dissimilarity focuses on the extent to which an employee differs from other employees in his or her work group based on certain characteristics. In this study we follow the employee dissimilarity stream. 
Employee dissimilarity can take on several forms; among those are visual dissimilarity and informational dissimilarity (Hobman, Bordia, \& Gallois, 2003). Visual dissimilarity is based on easily identifiable characteristics such as age, gender, and ethnic background. Informational dissimilarity is based on differences in the knowledge bases, skills, backgrounds, and experiences between an employee and his or her co-workers. It is necessary to distinguish between forms of dissimilarity because visual dissimilarity is more likely to evoke responses from coworkers based predominantly on stereotypes and biases (Milliken and Martins, 1996). In contrast informational dissimilarity can lead to problems that are task-related (Hobman, Bordia, \& Gallois, 2003). For example, employees who are high in informational dissimilarity can find that their approach to and knowledge of issues may differ significantly from co-workers and thus arriving at consensus solutions can be a challenge. In this study, we examine both forms of dissimilarity by capturing employee dissimilarity based on the characteristics of age, gender, education, and tenure.

Research on employee dissimilarity is based on three theories attraction-selection-attrition, social identity, and self-categorization (Chatman, Polzer, Barsade, \& Neale, 1998; Hobman, Bordia, \& Gallois, 2003; Pelled, Eisenhardt, \& Xin, 1999; Riordan \& Shore, 1997; Thomas, 1999; Tsui et al., 1992). The attraction-selectionattrition theory argues that people are naturally attracted to and influenced by people whom they perceive to be similar to themselves. Thus, in-groups and out-groups develop in which people who are dissimilar are considered part of an out-group. The related theories of self-categorization and social identity propose that part of an individual's self-concept is derived from his/her membership in a social group and the value and emotional significance attached to that membership. First, individuals classify themselves and others into groups through selfcategorization, which often involves comparisons based on salient characteristics such as race, ethnicity, and gender. This decision is a direct result of their desire to maintain a high level of self-esteem and a positive self-identity (Tajfel \& Turner, 1986). However, social identification often results in stereotypical perceptions of self and others that ultimately lead to ethnocentrism, prejudice, and discrimination (Ashforth \& Mael, 1989; Brickson, 2000). Those who are deemed to be out-group members may be perceived as less socially attractive or even less honest and trustworthy (Hobman, Bordia, \& Gallois, 2003).

Visual and information dissimilarity can result in employees bringing different perspectives to an organization and the tasks they complete. These dissimilarities contribute to increased levels of creativity found in culturally diverse organizations (Jackson, 1992). Therefore, organizations can benefit from creative decisions and problem solving by attracting and selecting individuals that are different. As such, dissimilar employees create heterogeneous groups that can have an advantage over homogeneous groups regarding creative tasks. According to McLeod, et al. (1996), "diverse groups will have a performance advantage over homogeneous groups on creativity tasks requiring knowledge of different cultures". This statement can be extended to include dissimilar employees based on both visual and informational differences.

In-groups and out-groups may also form as a result of conflict caused by information dissimilarity (Hobman, Bordia, \& Gallois, 2003). People who have similar educational backgrounds and experiences more easily identify and communicate with each other. Similarly, individuals whose tenure with the firm is on the same level may have similar knowledge and experience with the firm's policies and dynamics. Consequently, those high in information dissimilarity may find themselves to be part of the out-group.

Empirical evidence supports the hypothesis that diverse workgroups experience higher turnover (Jackson et al., 1991; O'Reilly et al., 1989; Wagner et al., 1984). Jackson (1992) found that the demographic composition of top management teams does indeed predict turnover rates with diverse teams experiencing higher turnover. Results indicate that the propensity to leave is associated with both the individual's dissimilarity and the group's heterogeneity. Evidence demonstrates that women and nonwhite men have higher intentions to quit than white men do. For example, African Americans have a turnover rate that is 40 percent higher than Whites (Bergmann \& Krause, 1968). Turnover rates for women are found to be 58 percent higher than for men (Meisenheimer, 1990).

A second explanation for the employee dissimilarity-turnover relationship can be found in the personorganization fit literature (Bretz \& Judge, 1994; Chatman, 1991; O’Reilly, Chatman, \& Caldwell, 1991; Schneider, 1987). For example, attraction-similarity-attrition research suggests that the better the fit between individual 
expectations and the reality of organizational life, the more likely an individual stays with the organization (Schneider, 1987). In addition, team members with dissimilar attributes are more likely to leave than those who possess similar characteristics (Jackson, Brett, Sessa, Cooper, Julin, \& Peyronnin, 1991). Thus, an organization comprised of people who are similar to each other will often drive out those individuals that are different which results in a homogeneous organization with low levels of diversity.

\section{Person-Organization Fit}

P-O fit research examines the compatibility of employees and their organizations (Kristoff, 1996). When values are shared between employees and their organizations, higher levels of P-O fit exist (Badovick \& Beatty, 1987). Previous research has offered strong support for the relationship between P-O fit and important outcomes such as performance, job satisfaction, intention to leave, and creativity. There is a positive relationship between P-O fit and employee performance. Holland (1985) stated that individuals will achieve greatest performance when their skills and traits fit those of the organization. In support of this statement, Caldwell \& O'Reilly (1990) found that P$\mathrm{O}$ fit is positively related to job performance.

Both employees and organizations seek situations in which both the employee and the organization are compatible. Previous research examining the relationship between P-O fit and turnover suggests that employees whose values match those of their organization are less likely to experience feelings of incompetence or anxiety (Chatman, 1991). In contrast, employees that do not have a strong fit will either self-select out or will be released by the organization. For this reason, employees who fit with the organization are likely to have higher job satisfaction and lower intentions to quit than those who do not. Several studies have found that employee perceptions of P-O fit are significantly related to intention to leave, as well as to job satisfaction, and organizational commitment (Caldwell \& O’Reilly, 1990; Chatman, 1991; Saks \& Ashforth, 1997; Vancouver et al., 1994).

P-O fit research also suggests that employees who have strong fit also possess certain degree of similarity or homogeneity (Lopez \& McMillan-Capehart, 2003). As a result, a criticism of P-O fit is that it results in employees who think similarly and thus there is less innovation in the organization.

\section{Relationship Between Employee Dissimilarity And P-O Fit}

We argue that the degree of dissimilarity between an employee and his or her co-workers will impact whether or not the employee feels that he or she fits in with the firm. In other words, employee dissimilarity will be negatively related to employee perceptions of P-O fit. Although no previous empirical research has specifically examined the relationship between employee dissimilarity and P-O fit, we can draw some conclusions based on related research findings. Hobman, Bordia, \& Gallois (2003) found that employees who perceive themselves to be dissimilar from their work group also experienced greater conflict with group members as well as task-related conflict. When employees are dissimilar from the prototypical group, either visually or due to information gaps, they are less likely to feel that they belong in the organization. As such, we offer the following proposition.

$\mathbf{P}_{1}$ : $\quad$ Employee dissimilarity will be negatively related to employee perceptions of P-O fit.

\section{The Moderating Impact Of The Organizational Climate And Socialization Tactics}

In the following section, we offer theoretical rational for the moderating impact of both organizational climate and socialization tactics on the relationship between employee dissimilarity and P-O Fit. Consequently, the following discussion fills a considerable gap in diversity research. First, we will define the moderating constructs, then we will offer theoretical support for the moderating relationship. 


\section{Organizational Climate}

Organizational climate reflects elements of the organizational environment, such as policies, processes, and values that are perceived by employees. Individual behaviors are often a result of perceptions of the work environment more so than of the reality of the work environment (James \& James, 1989). Thus, organizational climate perceptions are appropriate to study when the focus is on individual-level responses, as in this study.

Organizations communicate their expectations of employee behaviors through their organizational climate. We propose that certain climates are better at embracing diversity than other climates. In the current study, we focus on two dimensions of employee perceptions of the organizational climate that have emerged from research on how work is accomplished among people: individualism and collectivism (e.g. Early, 1993). The two dimensions should be thought of as opposing ends of a continuum. Neither is superior or inferior to the other. Both individualistic and collectivistic organizations have likely evolved as a result of their external environments (Chatman \& Barsade, 1995).

Organizations that emphasize individualism encourage employees to pursue individual goals and objectives by offering rewards based on individual achievement. Competition is encouraged in individualistic organizations and the use of teams to accomplish work is uncommon. Conversely, collectivistic organizations focus on shared objectives and cooperation. Teamwork is common in collectivistic organizations and consequently employees are rewarded based on the accomplishments of the group or organization. Collectivistic cultures often encourage employees to sacrifice their own personal interests for the attainment of organizational goals. Employees in collectivistic cultures are more likely to adjust their own behavior when differences in coworkers' behavior are noted.

\section{Organizational Climate As A Moderator}

Organizational culture sets the stage for the work environment. We propose that environments that rely on collectivistic climates will discourage the formation of in-groups and out-groups. Organizations that embrace employee differences create an environment in which "all members and their cultures are appreciated and utilized to achieve organizational success" (Richard \& Grimes, 1996: 165). Consequently though employees may be dissimilar, the negative outcomes of dissimilarity will be diminished while the positive outcomes will be reinforced.

Proposition 1 states that employee dissimilarity will be negatively related to perceptions of P-O fit. However, we argue that when organizations have a collectivistic climate this relationship is not as strong. Collectivistic organizational climates create a feeling of community. Research on individualistic and collectivistic organizations has found that employees in collectivistic organizations exhibit more cooperative behaviors and less conflict (Chatman \& Barsade, 1995; Chatman et al., 1998; Cox, 1994; McMillan-Capehart, 2005).

According to Chatman et al. (1998), the organization's "emphasis on either collectivism or individualism may particularly influence the social categorization process" (p. 751). A focus on individualism causes employees to pay greater attention to their own personal characteristics and to contrast them against others. This stimulates the social categorization process and focuses employees on individual characteristics. In contrast collectivism encourages teamwork, shared objectives, and group rewards. As a result, employees are encouraged to focus more on the organization and commonalities among people (Chatman et al., 1998). Consequently, employees in a collectivistic organization are more likely to use organizational membership as the basis for social categorization rather than individual characteristics (Chatman et al., 1998).

$\mathbf{P}_{2}$ : A collectivistic organizational climate will positively moderate the relationship between employee dissimilarity and perceptions of $\mathrm{P}-\mathrm{O}$ fit such that the negative relationship will be weaker (less negative). 


\section{Organizational Socialization}

Socialization helps determine the level of cultural congruence between the individual and the organization. Therefore, in an effort to increase perceptions of P-O fit, firms implement socialization tactics that are based on the organization's culture. As such, socialization plays an important role in determining P-O fit.

Jones (1986) adapted a set of socialization tactics first created by Van Maanen \& Schein (1979). This set involves six groups of socialization tactics that are grouped into two categories; individualized and institutionalized tactics (Van Maanen \& Schein, 1979; Jones, 1986). These tactics are the implemented in order to acclimate employees into the organization's overriding culture.

\section{Institutionalized Socialization Tactics}

Institutionalized socialization tactics refer to the way in which new employees are provided with explicit guidelines about the sequence and timing of progression in an organization (Allen \& Meyer, 1990). Institutionalized socialization refers to the way in which organizations provide employees with explicit guidelines about the sequence and timing of progression in an organization (Allen \& Meyer, 1990). It is characterized by a structured program that encourages a custodial role orientation (i.e. employees passively accept preset roles and thus maintain homogeneity) (Jones, 1986). Institutionalized socialization produces a more homogeneous organization where innovation is inhibited and employees respond to situations very similarly. According to Allen \& Meyer (1990), institutionalized socialization tactics may have a negative effect on creativity and innovation.

\section{Individualized Socialization Tactics}

Individualized socialization involves allowing employees to make decisions regarding how tasks should be performed. There are fewer schedules, guidelines, and procedures in an organization that implements individualized tactics. An organization that employs individualized socialization is more heterogeneous because innovation is encouraged and accepted. Individualized socialization tactics promote an organization that capitalizes on differing beliefs and values. In the past, these tactics have been positively related to performance but negatively related to conflict (Ashforth \& Saks, 1996; Jones, 1983, 1986).

Through encouraging employees to develop innovative roles and appreciating individuals' differing beliefs and values, organizations may create a workplace where dissimilar employees feel valued and an important part of the success of the organization. The use of individualized socialization tactics should result in mutual respect for one another and acknowledgement of the benefits associated with diversity (i.e. creativity, innovation, and problem solving). Individualized tactics should reduce discrimination in the workplace and provide more role models or mentors. As a result, dissimilar employees should not be excluded from the networks and social groups because these tactics encourage and promote staffing decisions regarding diverse individuals. Organizations will benefit from the positive consequences of diversity if tactics are used that encourage and promote diversity in the workplace. Therefore, organizations that seek to take advantage of the benefits associated with employee dissimilarity may experience the positive consequences and not the negative through using individualized tactics. This socialization process leads to a multicultural organization in which "all members and their cultures are appreciated and utilized to achieve organizational success (Richard \& Grimes, 1996: 165). The result is an increase in creativity, problem solving, job satisfaction, and organizational commitment and a decrease in conflict and turnover (Richard \& Grimes, 1996).

\section{Socialization as A Moderator}

Institutionalized socialization tactics often force individuals to fit the organization. Employees are forced to assimilate into the organization and assume the values and beliefs of the majority. This process can be very difficult for dissimilar individuals; especially those that wish to retain their own values (Richard \& Grimes, 1996).This forced assimilation will result in the creation of out-groups and in-groups. Dissimilar employees often experience lower job satisfaction, increased conflict, lower performance, and higher levels of intent to quit. In 
addition, diverse organizations that employ institutionalized tactics will experience lower levels of creativity and problem solving. In extreme cases of conflict associated with assimilation, individuals may experience acculturative stress (Berry, 1997). Acculturative stress involves the psychological, social, and physical health consequences involved when individuals of different cultures come into contact and experience subsequent changes in their cultural patterns (Olmedo, 1979). Organizations with high levels of diversity and therefore lower levels of P-O fit experience the negative effects related to conflict and turnover because of the improper socialization of new employees (McMillan-Capehart, 2005).

Individualized socialization tactics promote a heterogeneous organization that capitalizes on differing beliefs and values. In the past, these tactics have been positively related to performance but negatively related to conflict (Ashforth \& Saks, 1996; Jones, 1983, 1986). It is logical however, that the negative relation to conflict is due to matching improper tactics with an organization's culture. For example, an organization that has a collectivistic culture and high levels of cultural diversity will benefit from using socialization tactics that encourage employees to draw upon their experiences, beliefs, and values in order to solve problems and make decisions.

$\mathbf{P}_{3}$ : Individualized socialization tactics will positively moderate the relationship between employee dissimilarity and perceptions of P-O fit such that the negative relationship will be weaker (less negative).

\section{DISCUSSION}

According to McMillan \& Lopez (2001), the debate regarding fit versus diversity is a rich one. Some argue that by its fundamental nature P-O fit is achieved at the expense of diversity. Schneider, Goldstein, \& Smith (1995) discuss the ongoing debate between P-O fit and diversity as the difference between homogeneous and heterogeneous organizations. They propose that "homogeneity is positive for organizational survival" because shared values and culture facilitate communication and cooperation (1995:766). However, it is possible that homogeneity also stifles creativity and innovativeness. It is the purpose of this paper to introduce a framework that could be used to understand how organizations can benefit from increasing employee dissimilarity while still achieving the positive effects of P-O fit.

This research suggests that despite the apparent conflict between dissimilarity and P-O fit, it is possible to create a workforce that is both diverse and shares similar organizational values. By creating the appropriate organizational culture and then reinforcing that climate through the correct socialization tactics, firms will benefit from the positive effects of diversity and P-O fit. In other words, organizations can experience the creativity, decision making, and problem solving of diversity while still enjoying lowered relationship conflict and turnover along with increased job satisfaction of P-O fit.

Diversity is a part of our society and therefore the workforce. We know that some degree of fit among employees is necessary to have harmony; on the other hand extreme levels of fit can lead to negative consequences such as lessened creativity. This is a dilemma many companies now face. Through this research, we have offered one possible solution to this dilemma. By being attentive to the organizational climate and to the manner in which employees are socialized, it is possible that managers can nurture dissimilar employees so that they fit well with the organization while maintaining their uniqueness.

\section{REFERENCES}

1. Ashforth, B. E., and Mael, F., (1989) Social identity theory and the organization, Academy of Management Review, 14 (1), pp. 20-39.

2. Ashforth, B. E., and Saks, A., (1996) Socialization tactics: Longitudinal effects on newcomers' adjustment, Academy of Management Journal, 39 (1), pp. 149-178.

3. Badovick, Gordon J., and Beatty, S. E., (1987) Shared organizational values: Measurement and impact upon strategic marketing implementation, Journal of the Academy of Marketing Science, 15(1), pp. 19-26.

4. Bergmann, B.R., \& Krause, W.R., (1968) Evaluating and forecasting progress in racial integration of employment, Industrial and Labor Relations Review, 18, pp. 399-409.

5. Bluedorn, A. C., (1982) The theories of turnover: Causes, effects, and meaning in S. B. Bacharach (Ed.), Research in the Sociology of Organizations, JAI, Greenwich, CT, Vol. 1, pp. 75-128. 
6. Bretz, R. D., and Judge, T. A., (1994) The role of human resource systems in job applicant decision processes, Journal of Management, 20(3), pp. 531-551.

7. Brickson, S., (2000) The impact of identity orientation on individual and organizational outcomes in demographically diverse settings Academy of Management Review, 25(1), pp. 82-101.

8. Caldwell, D., Chatman, J., and O'Reilly, C., (1990) Building organizational commitment: A multi-firm study Journal of Occupational Psychology, 63, pp. 245-261.

9. Carrell, M., and Mann, E., (1995) Defining workforce diversity in public sector organizations, Public Personnel Management, 24(1), pp. 99-113.

10. Chao, G., O’Leary-Kelly, A., Wolf, S., Klien, H., and Gardner, P., (1994), Organizational socialization: Its content and consequences, Journal of Applied Psychology, 79 (5), pp. 730-743.

11. Chatman, J. A., (1991), Matching people and organizations: selection and socialization in public accounting firms, Administrative Science Quarterly, 36, pp. 459-484.

12. Chatman, J.A., and Barsade, S.G., (1995) Personality, organizational culture, and cooperation: Evidence from a business simulation. Administrative Science Quarterly, 40, pp. 423-443.

13. Chatman, J.A., Polzer, J.T., Barsade, S.G., and Neale, M.A., (1998). Being different yet feeling similar: The influence of demographic composition and organizational culture on work processes and outcomes, Administrative Science Quarterly, 43, pp. 749-780.

14. Cox, T. J. (1994), Cultural diversity in organizations, Barrett-Koehler Publishers, San Francisco.

15. Hobman, E. V., Bordia, P., and Gallois, C. (2003), Consequences of feeling dissimilar from others in a work team Journal of Business and Psychology, 17, pp. 301-325.

16. Holland, J. L. (1985), Making vocational choices, Prentice-Hall, Englewood Cliffs, NJ.

17. Huo, Y.P., Huang, J.H., and Napier, N.K. (2002), Divergence or convergence: A cross-national comparison of personnel selection practices, Human Resource Management, 41(1), pp. 31-44.

18. Jackson, S. E. (1992), Team composition in organizational settings: Issues in managing an increasingly diverse work force, In S. Worchel, W. Wood and J. A. Simpson (Eds.), Group Process and Productivity, Sage Publications Inc, Newbury Park, CA. pp. 138-173.

19. Jackson, S., Brett, J., Sessa, V., Cooper, D., Julin, J., and Peyronnin, K. (1991). Some differences make a difference: Individual dissimilarity and group heterogeneity as correlates of requirement, promotions, and turnover, Journal of Applied Psychology, 76 (5), pp. 675-689.

20. James, L.A., and James, L.R. (1989), Integrating work environment perceptions: Explorations into the measurement of meaning, Journal of Applied Psychology, 74, pp. 739-751.

21. Jones, G.R. (1983), Psychological orientation and the process of organizational socialization: An interactionist perspective, Academy of Management Review, 8, pp. 464-474.

22. Jones, G. (1986), Socialization tactics, self-efficacy, and newcomers' adjustment to organizations Academy of Management Journal, 29 2, pp. 262-279.

23. Kristof, A. L. (1996), Person-organization fit: An integrative review of its conceptualizations, measurement, and implications, Personnel Psychology, 49, pp. 1-49.

24. Louis, M. (1980), Surprise and sense-making: What newcomers experience in entering unfamiliar organizational settings, Administrative Science Quarterly, 25, pp. 226-251.

25. McLeod, P., Lobel, S., and Cox, T. (1996), Ethnic diversity and creativity in small groups, Small Group Research, 27 (2), pp. 248-264.

26. Meisenheimer, J.R. (1990), Employee absences in 1989: A new look at data from the CPS, Monthly Labor Review, August, pp. 28-33.

27. Meyer, J. P., Allen, N. J., and Gellatly, I. R. (1990), Affective and continuance commitment to the organization: Evaluation of measures and analysis of concurrent and time-lagged relations, Journal of Applied Psychology, 75, pp. 710-720.

28. Milliken, F., and Martins, L. (1996), Searching for common threads: Understanding the multiple effects of diversity in organizational groups, Academy of Management Review, 21 (2), pp. 402-433.

29. O'Reilly, C. A., III, Caldwell, D., and Barnett, W. (1989), Work group demography, social integration, and turnover, Administration Science Quarterly, 34, pp. 21-37.

30. O'Reilly, C.A., Chatman, J., and Caldwell, D.F. (1991), People and organizational culture: A profile comparison approach to assessing person-organization fit. Academy of_Management Journal, 34(3), pp. 487-516. 
31. Pelled, L.H., Eisenhardt, K.M., \& Xin, K.R. (1999), Exploring the black box: An analysis of work group diversity, conflict and performance, Administrative Science Quarterly, 44(1), pp. 1-2.

32. Richard, O. C. (2000), Racial diversity, business strategy, and firm performance: A resource- based view, Academy of Management Journal, 43, 2, pp. 164-177.

33. Richard, O.C. \& Grimes, D. (1996). Bicultural interrole conflict: An organizational perspective, The MidAtlantic Journal of Business, 32 (3), pp. 155-270.

34. Riordan, C. M., and Shore, C. (1997), Demographic diversity and employee attitudes: An empirical examination of relational demography within work units, Journal of Applied Psychology, 82, pp. 342-358.

35. Riordan, C. M., Weatherly, E.W., Vandenberg, R.J., and Self, R.M. (2001), The effects of pre-entry experiences and socialization tactics on newcomer attitudes and turnover, Journal of Managerial Issues, 13(2), pp. 159-176.

36. Schneider, B. (1987), The people make the place, Personnel Psychology, 40, pp. 437-453.

37. Tajfel, H., and Turner, J. C. (1986), The social identity theory of inter-group behavior. In S. Worchel \& L. W. Austin (Eds.), Psychology of Intergroup Relations, Nelson-Hall, Chicago.

38. Thomas, D. 1999. Cultural diversity and work group effectiveness. Journal of Cross Cultural Psychology, 30(2): 242-263.

39. Tsui, A.S., Egan, T.D., and O'Reilly III, C.A. (1992), Being different: Relational demography and organizational attachment, Administrative Science Quarterly, 37, pp. 549-579.

40. Vancouver, J.B., Millsap, R.E., and Peters, P.A. (1994), Multilevel analysis of organizational goal congruence. Journal of Applied Psychology, 79, pp. 666-679.

41. Van Maanen, J., and Schein, E. H. (1979), Toward a theory of organizational socialization. In B.M. Staw (Ed.), Research in Organizational Behavior, 1, JAI Press, Greenwich, CT.

42. Wagner, W., Pfeffer, J., and O'Reilly, C. (1984), Organizational demography and turnover in topmanagement group, Administrative Science Quarterly, 29, pp. 74-92.

43. Watson, W., Kumar, K., \& Michaelson, L. (1993), Cultural diversity's impact on interaction process and performance: Comparing homogeneous and diverse task groups, Academy of Management Journal, 36 (3), pp. 590-602.

44. Wharton, A., and Baron, J. (1987), So happy together? The impact of gender segregation on men at work, American Sociological Review, 52, pp. 574-587.

45. Zenger, T., and Lawrence, B. (1989), Organizational demography: The differential effects of age and tenure distributions on technical communication, Academy of Management Journal, 42, pp. 353-376.

\section{NOTES}




\section{NOTES}

